Review Article

\title{
Antioxidative Effects of Natural Products on Diabetic Cardiomyopathy
}

\author{
Bingdi Yan, ${ }^{1}$ Jin Ren, ${ }^{1}$ Qinghua Zhang, ${ }^{1}$ Rong Gao, ${ }^{1}$ Fenglian Zhao, ${ }^{2}$ Junduo Wu, ${ }^{3}$ and \\ Junling Yang ${ }^{1}$ \\ ${ }^{1}$ Department of Respiratory Medicine, The Second Hospital of Jilin University, 218 Ziqiang Street, Changchun 130041, China \\ ${ }^{2}$ Department of Clinical Laboratory, The Second Hospital of Jilin University, 218 Ziqiang Street, Changchun 130041, China \\ ${ }^{3}$ Department of Cardiology, The Second Hospital of Jilin University, 218 Ziqiang Street, Changchun 130041, China
}

Correspondence should be addressed to Junduo Wu; wujd@jlu.edu.cn and Junling Yang; junling@jlu.edu.cn

Received 3 May 2017; Revised 8 July 2017; Accepted 6 August 2017; Published 18 October 2017

Academic Editor: Robertina Giacconi

Copyright (C) 2017 Bingdi Yan et al. This is an open access article distributed under the Creative Commons Attribution License, which permits unrestricted use, distribution, and reproduction in any medium, provided the original work is properly cited.

\begin{abstract}
Diabetic cardiomyopathy (DCM) is a common and severe complication of diabetes and results in high mortality. It is therefore imperative to develop novel therapeutics for the prevention or inhibition of the progression of DCM. Oxidative stress is a key mechanism by which diabetes induces DCM. Hence, targeting of oxidative stress-related processes in DCM could be a promising therapeutic strategy. To date, a number of studies have shown beneficial effects of several natural products on the attenuation of DCM via an antioxidative mechanism of action. The aim of the present review is to provide a comprehensive and concise overview of the previously reported antioxidant natural products in the inhibition of DCM progression. Clinical trials of the antioxidative natural products in the management of DCM are included. In addition, discussion and perspectives are further provided in the present review.
\end{abstract}

\section{Introduction}

Diabetes mellitus (DM) is one of the most common metabolic disorders, encountered in human populations worldwide. The number of adult diabetic patients was 285 million in 2010, and it is estimated to increase to 439 million by 2030 [1]. Persistent hyperglycemia can cause damage to various organs, including the heart, via different modes of action [2]. Amongst the numerous complications of DM, cardiovascular complications namely, hypertension, coronary heart disease, and diabetic cardiomyopathy (DCM) are the main causes of morbidity and mortality. DCM accounts for nearly $80 \%$ of the mortality noted in diabetic patients [3]. DCM is initially defined as the presence of abnormal myocardial structure and function in the absence of coronary artery disease, hypertension, and valvular disease [4]. Recent studies have proposed that DCM would be a result of a longlasting process in which the myocardium is affected at a very early stage by metabolic changes prior to the diagnosis of
DM [5]. This process progresses rapidly by the incidence of myocardial ischemia [5].

The clinical features of DCM include diastolic dysfunction at an early stage and systolic dysfunction at a late stage which result in reduced left ventricular function, early heart failure, myocardial fibrosis, and death [6]. This procedure is not accompanied by hypertension or coronary heart disease. Some patients may have no symptoms and/or mild diastolic dysfunction at the early stage, while with the progression of DCM, the patients may develop the following symptoms: shortness of breath, fatigue, weakness, and ankle edema [7].

The main cause of the pathological change of DCM is microangiopathy, which results in cardiac structural and functional alterations, such as apoptosis of the myocardium, myocardial interstitial fibrosis, and perfusion abnormality of the heart muscles. It was reported that capillary basement membrane thickening and microaneurysms were observed in patients with DCM $[8,9]$. Once the myocardial interstitial fibrosis has developed, it cannot be reversed and a poor 
prognosis of the diseases is frequently expected. Consequently, it is imperative to identify appropriate therapeutic targets notably at the early stage of DCM.

The pathogenesis of DCM has not been fully elucidated. Various biological processes have been shown to account for the pathogenesis and progression of DCM, including, but not are limited to, oxidative stress, cardiomyocyte apoptosis, disordered calcium handling, endoplasmic reticulum stress, myocardial insulin resistance, endothelial dysfunction, mitochondrial dysfunction, and autophagy [10, 11]; amongst which, oxidative stress is believed to be a key mechanism through which DM induces DCM. Despite a few reports regarding the antioxidative effects of natural products on DCM, a systematic review, to date, has not been provided. Here, we summarize the previous findings and provide perspectives and indications for future studies.

\section{Role of Oxidative Stress in DCM}

Reactive oxygen species (ROS) are chemically reactive chemical species containing oxygen, including peroxides, superoxide, hydroxyl radical, and singlet oxygen [12]. Mitochondrion is the main "factory" in which DM produces excessive mitochondrial superoxide [13]. The DMinduced overproduction of mitochondrial superoxide leads to increased formation of advanced glycosylation end products (AGEs), expression of the receptor for AGEs (RAGE), and activation of protein kinase $\mathrm{C}(\mathrm{PKC})$, the polyol pathway, and the hexosamine pathway [14]. In case of the excess ROS not being balanced and/or removed via the action of endogenous antioxidative enzymes and/or exogenous antioxidant molecules, an increased oxidative stress occurs, which can result in damage to proteins, lipids, and DNAs in cardiomyocytes [15]. These detrimental effects eventually lead to the remodeling of the diabetic heart, followed by its dysfunction (Figure 1).

\section{Signaling Pathways in the Regulation of Oxidative Stress in DCM}

The excess production and inefficient removal of ROS causes the induction of oxidative stress. The improvement of the antioxidative mechanisms and the suppression of the oxidative stress are considered as key targets in the treatment of DCM. Key factors, such as nuclear factor erythroid 2related factor 2 (Nrf2), RAGE, nicotinamide adenine dinucleotide phosphate (NADPH) oxidase (NOX), and peroxisome proliferator-activated receptor (PPAR), have notably been investigated with regard to the inhibition of oxidative stress (Figure 1).

3.1. Nrf2 Signaling. Nrf2 is a member of the cap ' $n$ ' collar family of proteins. The gene encoding Nrf2 belongs to a subset of basic leucine-zipper (bZip) genes that was reported to act as an essential regulator of antioxidative activity and electrophilic signaling [16]. Nrf2 can promote the expression and production of detoxification enzymes and antioxidant proteins, which contribute to the clearance of ROS and the restoration of the prooxidant/antioxidant balance [17-19]. Nrf2 combines with Kelch-like ECHassociated protein 1 (Keap1), which can rapidly degrade Nrf2 through ubiquitination by proteasome [20]. Certain chemical inducers, such as heavy metals, oxidizable diphenols, and Michael acceptors, can modify the cysteine residues in Keap1 that act as nucleophiles and activate Nrf2 by suppressing the degradation of the protein [20]. Under physiological conditions, Nrf2 combines with Keap1 in the cytoplasm, whereas under oxidative stress conditions, Nrf2 dissociates from Keap 1 and translocates to the nucleus. The activated Nrf2 protein then binds antioxidant-responsive elements within the promoter regions of the antioxidant genes and induces transcription of a series of antioxidant enzymes, including NADPH quinone oxidoreductase (NQO1), glutathione-S-transferase (GSH), heme oxygenase1 (HO-1), and $\gamma$-glutamylcysteine synthetase $[18,21-23]$ (Figure 1). Nrf2 is a key protective factor in a multitude of diseases, such as cancer [24], chronic degenerative pathology [25], metal-induced toxicities [26], and angiotensin II-induced apoptosis of testicular cells [27]. Recent studies demonstrated that Nrf2 was essential in the prevention of high glucose-induced oxidative damage in cardiomyocytes, endothelial cells and vascular smooth muscle cells [28-30], and in animal models of DCM [31]. It was reported that $\mathrm{Nrf2}$ knockout mice were prone to develop severe cardiomyopathy in a streptozotocin-induced diabetic model compared with wild-type mice [31]. These findings confirmed the protective function of Nrf2 in DCM. Therefore, the activation of Nrf2 is considered as a promising therapeutic target for the treatment of DCM.

3.2. RAGE Signaling. RAGE is a multiligand cell surface receptor, which can be activated by a wide range of ligands, such as AGEs [32] and amphoterin [33]. RAGE is expressed in numerous normal cell types, including cardiomyocytes [34], endothelial cells [35], mononuclear phagocytic cells [36], and vascular smooth muscle cells [37]. Under diabetic condition, the DM-induced formation of AGEs binds RAGE that is expressed on the cell membrane of cardiomyocytes and endothelial cells, leading to the production of ROS, proinflammatory cytokines, and the activation of nuclear factor kappa B $(\mathrm{NF}-\kappa \mathrm{B})$. NF- $\kappa \mathrm{B}$, in turn, activates the expression of RAGE [38], resulting in more severe oxidative damage. AGEs/RAGE is positively involved in the activation of NOX [39]. It has been shown that the AGE/RAGE-induced ROS interaction with NOX to generate more ROS in human endothelial cells isolated from patients with type 1 diabetes (T1DM) [39]. The data demonstrated a cross-talk between NOX and AGE/RAGE signaling, as a positive feedback loop (Figure 1). The studies proposed that the inhibition of the AGE/RAGE signaling pathway can effectively reduce DM-induced oxidative stress, thereby ameliorating DCM.

3.3. NOX Signaling. NOXs contribute to the production of superoxide and hydrogen peroxide $\left(\mathrm{H}_{2} \mathrm{O}_{2}\right)$ under pathological conditions [40]. There are 7 vascular NOX isoforms in total; amongst which, NOX1, NOX2, and NOX4 are highly expressed in the diabetic heart [41]. NOX4 is the major 


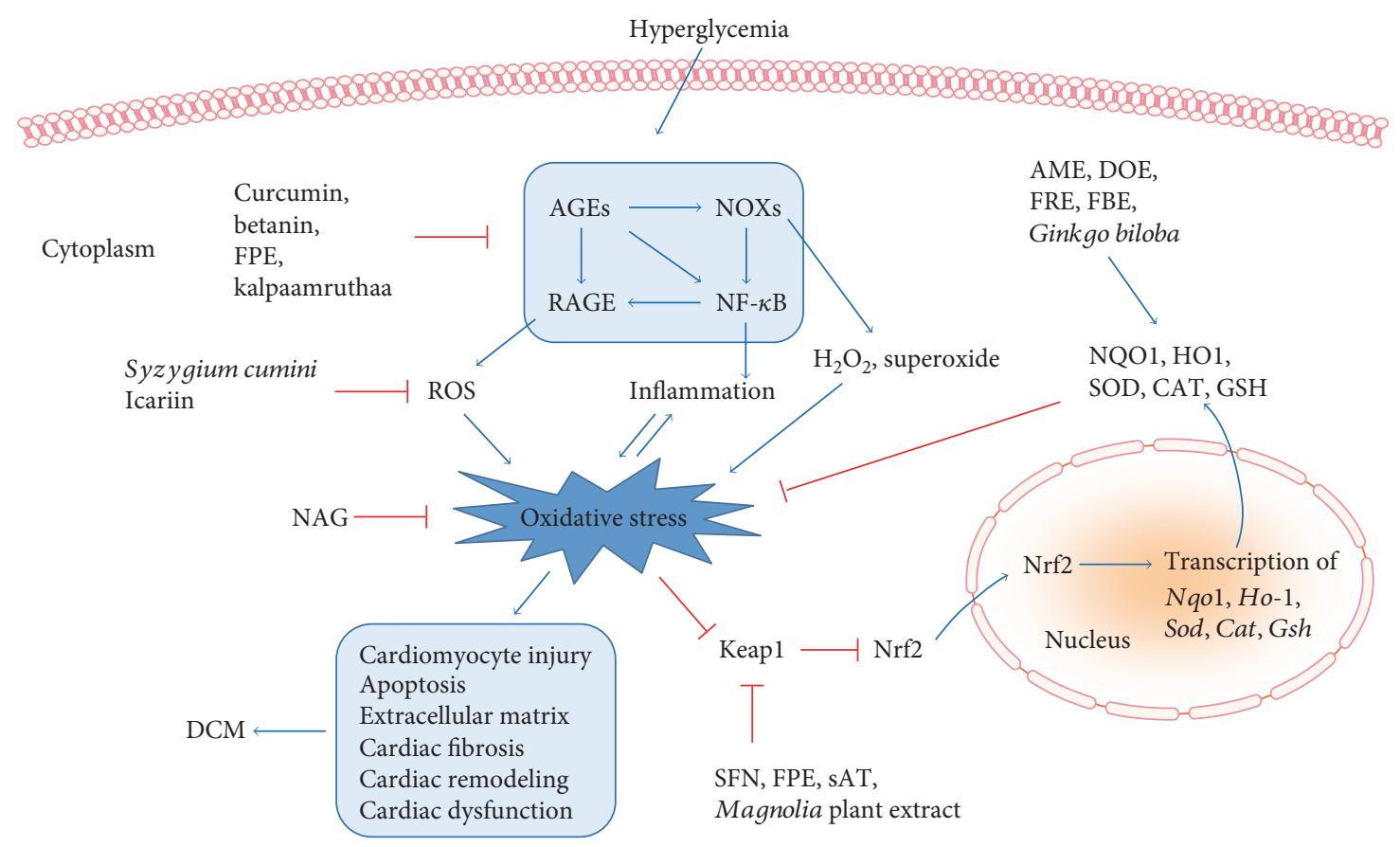

FIGURE 1: Role of antioxidative natural products in diabetic cardiomyopathy. Diabetes causes the formation of AGEs, leading to the activation of NOXs and RAGE, the effects of which induce overproduction of ROS, H2O2, and superoxide, followed by enhanced oxidative stress. AGEs can activate NF- $\kappa$ B both directly and indirectly through NOXs, resulting in inflammation, a status that positively amplifies oxidative stress and vice versa. Consequently, the diabetes-elevated oxidative stress can cause cardiomyocyte injury, apoptosis, accumulation of extracellular matrix, cardiac fibrosis, remodeling, and dysfunction, all of which are hallmarks of DCM. These effects can be blocked or blunted by several natural products, functioning through different targets. Curcumin, betanin, FPE, and kalpaamruthaa were reported to inhibit the AGE/RAGE/NOX/NF- $\kappa$ B pathway. Syzygium cumini and icariin decreased the formation of ROS. NAG had the ability to diminish diabetes-induced oxidative stress. In addition, several natural products were shown to elevate antioxidant capacity, via activating Nrf2 antioxidant system. SFN, FPE, sAT, and Magnolia plant extract inactivated Keap1, the key negative regulator of Nrf2, leading to the release of Nrf2. This effect facilitated nuclear translocation of Nrf2, resulting in the transcription of various antioxidant genes, such as Nqo1, Ho-1, Sod, Cat, and Gsh. As a result, these antioxidants were increased in the cytoplasm, acting as scavengers for the diabetesinduced excessive free radicals. AME, DOE, FRE, FBE, and Ginkgo biloba were reported to elevate the activity of these antioxidants. Collectively, the natural products, functioning either through blocking the formation of oxidative stress or through enhancing the scavenging activity, ameliorated DCM in experimental models. AGEs: advanced glycosylation end products; AME: Aegle marmelos leaf extract; CAT: catalase; DCM: diabetic cardiomyopathy; DOE: Dendrobium officinale extract; FBE: Ficus racemosa stem bark extract; FPE: Flos Puerariae; GSH: glutathione; HO-1: heme oxygenase-1; Keap1: Kelch-like ECH-associated protein 1; NAG: North American ginseng; NF- $\kappa$ B: nuclear factor kappa-light-chain-enhancer of activated B cells; NOX: NADPH oxidase; NQO1: NADPH quinone oxidoreductase; Nrf2: nuclear factor erythroid 2-related factor 2; RAGE: receptor for AGEs; ROS: reactive oxygen species; sAT: Aralia taibaiensis; SFN: sulforaphane; SOD: superoxide dismutase; $\uparrow$ : activation or improvement; $\perp$ : inhibition or downregulation.

NOX isoform that is expressed in cardiomyocytes [42] and has been demonstrated to be an important source of ROS (Figure 1). NOX4 is localized in the endoplasmic reticulum [43] and nucleus [44], interacting with NADPH as an electron donor, producing $\mathrm{H}_{2} \mathrm{O}_{2}$ or superoxide [45].

Increased NOX4 expression was found in the left ventricles of streptozotocin- (STZ-) induced diabetic rats [41]. This result was further confirmed in high glucose-cultured cardiomyocytes [41]. Moreover, treatment of high glucose-cultured cardiomyocytes with antisense NOX4 abrogated the high glucose-induced ROS production. In addition to the protective effect of NOX4 inhibition on high glucose- (HG-) induced cardiomyocyte injury, the beneficial effect of this approach was found in HG-treated neonatal cardiac fibroblasts as well [46], the result of which is in line with the finding that NOX4 plays an essential role in the differentiation of myofibroblasts $[47,48]$. Hence, these studies suggest that the
NOX4-inhibiting approach could be a promising strategy in the prevention of DCM.

\section{Antioxidative Role of Natural Products in DCM}

The antioxidative effect of natural products on the attenuation of DCM has been extensively investigated in recent years [49], showing promising outcomes. These natural products and their functions and mechanisms are listed below and in Table 1 and summarized in Figure 1.

4.1. Sulforaphane (SFN). SFN, initially isolated from broccoli sprouts, is a well-known activator of Nrf2 [50] and was intensively studied for its effects in diabetic complications in recent years $[18,31,51-54]$. SFN activates Nrf2 


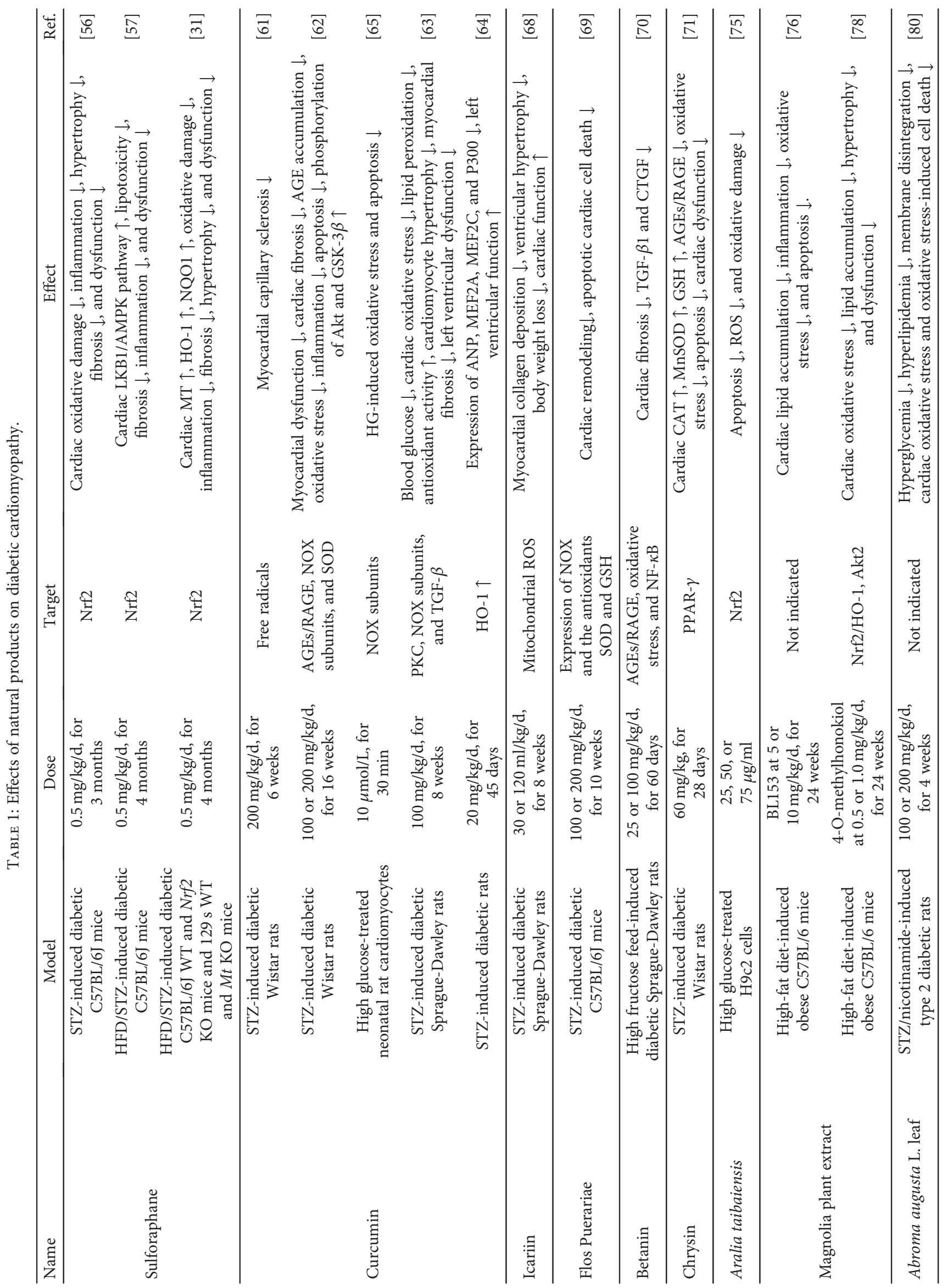




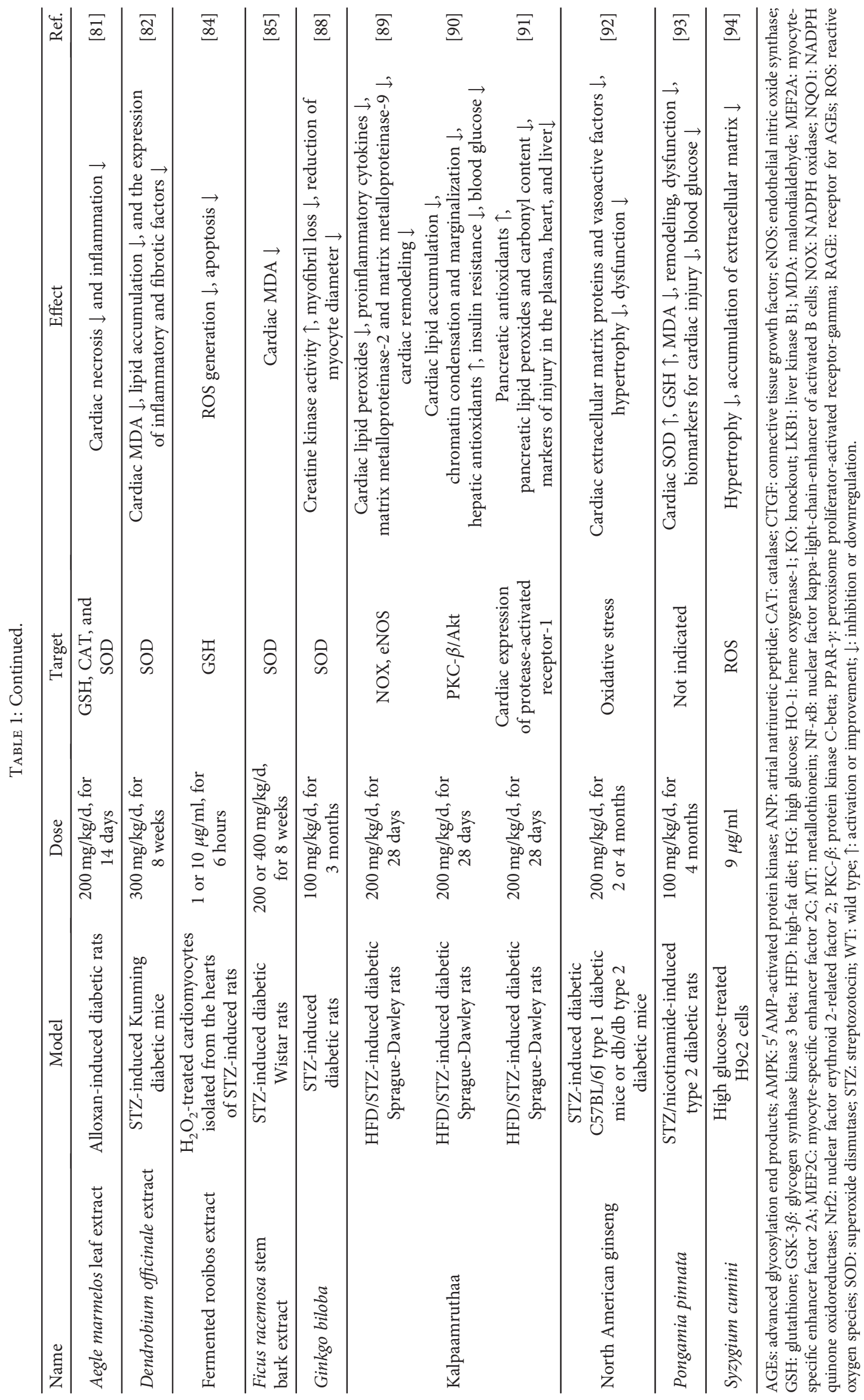


through inactivation of Keap1, via modifying specific residues within Keap1 protein [55].

In a STZ-induced mouse model of DM, treatment with SFN for either 3 months or 6 months significantly activated Nrf2 signaling and prevented DM-induced cardiac oxidative damage, inflammation, hypertrophy, fibrosis, and dysfunction [56]. Nrf2 played a crucial role in the protective effect of SFN, at least on HG-induced fibrotic response in cultured cardiomyocytes, since SFN lost this effect in the presence of Nrf2 siRNA [56]. Similarly, in a mouse model of type 2 diabetes (T2DM), SFN was able to activate Nrf2 antioxidant signaling, the effect of which restored the oxidative stressinduced inhibition of liver kinase B1/5' AMP-activated protein kinase (LKB1/AMPK) signaling pathway and prevented T2DM-induced lipotoxicity and cardiomyopathy [57]. The crucial role of Nrf2 in mediating the protection by SFN against DCM was further demonstrated by using Nrf2 knockout mice [31]. Moreover, metallothionein, a potent antioxidant [58], was identified to be a downstream target of Nrf2 and predominantly mediated SFN's protective effects on diabetic nephropathy [18] and DCM [31]. The effect of SFN has been tested in a double-blind clinical trial of T2DM, showing a significant improvement of insulin resistance [59]. In addition to the improvement of insulin resistance [59], SFN has the advantage of ameliorating DCM and therefore has a good potential for the use in future clinical trials of DCM.

4.2. Curcumin. Curcumin is a natural compound isolated from turmeric and has been widely used in indigenous medicine. Attention has been paid to the antioxidative effect of curcumin on DCM [60]. Curcumin was found to reduce myocardial capillary sclerosis [61]; attenuate cardiac tissue damage, myocardial cell hypertrophy, and apoptosis; reduce extracellular protein accumulation; and preserve left ventricular function [62-64] in the hearts of STZ-induced diabetic rats. Mechanistically, curcumin was found to increase HO-1 [64], catalase (CAT), superoxide dismutase (SOD), and GSH [61]. In addition, the ability to reduce the expression of the NOX subunits p22 phox, p47 phox, p67 phox, and gp91 phox could also account for curcumin's protective effects on DCM $[62,63]$. In HG-cultured neonatal rat cardiomyocytes, curcumin suppressed the expression of the NOX subunit Racl and reduced HG-induced oxidative stress, the effect of which inhibited the HG-induced apoptotic cell death [65].

Although curcumin was found to have antioxidative effects on DCM, the exact target through which curcumin exerted the functions remained unclear. Gene knockout and silencing approaches could aid the investigation of the exact mechanism of antioxidative function induced by curcumin. Furthermore, curcumin exhibits a poor bioavailability in plasma and in target tissues which may hinder its therapeutic efficacy [22]. Therefore, the improvement of the pharmacokinetics and the increase in the plasma concentration of curcumin are significant therapeutic targets in the application of curcumin for the treatment of DCM. Recently, C66, a curcumin derivative with much a higher bioavailability $[22,66]$, was found to activate Nrf2 and its downstream antioxidants in the kidneys and aortas of the STZ-induced diabetic mice $[22,67]$. Nrf2 played a prominent role in the C66 protection against diabetic nephropathy, since C66 lost partial, but significant, protection against the DM-induced renal damage [22] in the Nrf2 knockout mice. Future studies need to focus on the bioavailability and off-target effects of curcumin.

4.3. Icariin. Icariin was reported to inhibit mitochondrial oxidative stress and increase SOD activity in the hearts of the STZ-induced diabetic rats. Icariin was shown, in this study, to reduce myocardial collagen deposition, inhibit ventricular hypertrophy, reverse the DM-induced body weight loss, and improve cardiac function [68]. These results may indicate the efficiency of inhibiting mitochondrial ROS generation and increasing antioxidant capacity in ameliorating DCM. However, blood glucose levels were not indicated by this report, the result of which might be important to know whether the amelioration of DCM was caused by the icariin reduction of oxidative stress or by the amelioration of DM.

4.4. Flos Puerariae (FPE). FPE was shown to inhibit gp91 phox and p47 phox, the two subunits of NOX in the hearts of STZ-induced C57BL/6J diabetic mice [69]. Additionally, FPE inhibited the DM-induced ROS generation and enhanced the activity of SOD and glutathione peroxidase (GSH-Px), maintained myocardial structure, and attenuated DM-induced apoptotic cardiac cell death [69]. Thus, FPE had the capability to both inhibit NOX expression and upregulate the expression of antioxidants in the hearts of the diabetic mice. Despite the speculation of c-Jun N-terminal kinase and P38 mitogen-activated protein kinase to be the target of FPE, further investigations are needed to elucidate the mechanism of this natural product in the amelioration of DCM.

4.5. Betanin. Betanin, extracted from natural pigments, was shown by Han et al. to have a protective effect against high fructose feed-induced diabetic cardiac fibrosis in SpragueDawley rats [70]. The DM-induced expression of the cardiac profibrotic factors transforming growth factor $\beta$ (TGF- $\beta$ ) 1 and connective tissue growth factor were significantly inhibited by betanin. The further mechanistic study revealed the efficacy of betanin in inhibiting the AGE/RAGE signaling, oxidative stress, and NF- $\kappa \mathrm{B}$ under the diabetic condition. Given that cardiac fibrosis is a hallmark of DCM and contributes to cardiac dysfunction, the remarkable effect of betanin on the inhibition of fibrotic signaling should attract attention for the future studies on DCM.

4.6. Chrysin. Chrysin is a natural flavonoid that has antioxidative activity [71]. In a rat model of myocardial injury induced by STZ followed by isoproterenol injection, chrysin was found to activate PPAR- $\gamma$; upregulate CAT, MnSOD, and GSH; inhibit AGE/RAGE signaling and oxidative stress; and attenuate apoptosis [71]. These results provided evidence for PPAR- $\gamma$ activation in the potential management of DCM. However, more studies are needed to clarify the exact role of chrysin and other PPAR- $\gamma$ activators in ameliorating DCM. 
4.7. Aralia taibaiensis ( $s A T)$. sAT, with antioxidative property $[72,73]$, is a traditional Chinese medicine that is frequently used in patients with DM [74]. Recently, sAT was reported to activate Nrf2 signaling and reduce HG and glucose oxidase-induced apoptosis, ROS, and oxidative damage in cardiomyocytes [75]. Nrf2 was the key factor through which sAT exerted the protection, since the effects of sAT were markedly abolished in the presence of the Nrf2 siRNA.

4.8. Magnolia Plant Extracts (BL153 or 4-O-Methylhonokiol). BL153 showed beneficial effects on high-fat diet-induced cardiac [76] and aortic damage [77], via inhibition of oxidative stress. In addition, it has been shown that 4-Omethylhonokiol (MH), a bioactive constituent of BL153, reduced high-fat diet- (HFD-) induced cardiac pathological changes, including increased heart weight and abnormal echocardiography parameters [78]. The observation of the enhanced Nrf2/HO-1 signaling in the hearts of the $\mathrm{MH}$ treated mice [78] could be responsible for the decreased oxidative stress by MH. Both BL153 and MH had the capability to lower serum lipid level and improve insulin resistance in HFD animal models [79]. The effect of BL153 and MH should be tested in future studies on animal models of T1DM, since Nrf2 was shown to play a key role in protection against DCM in T1DM.

4.9. Abroma augusta L. Leaf. The effect of Abroma augusta L. leaf, a natural product that is traditionally used in treatment of DM in India and South Asia, was tested in a streptozotocin-nicotinamide-induced rat model of T2DM [80]. Abroma augusta L. leaf was found to reduce hyperglycemia, hyperlipidemia, membrane disintegration, oxidative stress, and oxidative stress-induced cell death in the kidneys and hearts of the diabetic rats [80]. Phytochemical screening revealed the presence of taraxerol, flavonoids, and phenolic compounds in Abroma augusta L. leaf [80]. Therefore, the specificity and off-target effects of this natural extract needs further investigation, although the doses provided in this study did not produce side effects in the diabetic rats.

4.10. Aegle marmelos Leaf Extract (AME). AME was studied in a rat model of alloxan-induced DM for its effect on earlystage DCM [81]. The results showed that AME evidently increased the antioxidants GSH, CAT, and SOD and rescued the DM-induced cardiac necrosis and inflammation [81].

4.11. Dendrobium officinale Extract (DOE). DOE, a traditional Chinese medicine, was shown to elevate the antioxidant SOD and decrease the production of malondialdehyde (MDA), the accumulation of lipid, and the expression of the fibrotic factors TGF- $\beta$, collagen-1, and fibronectin, as well as the inflammatory factors NF- $\kappa \mathrm{B}$, tumor necrosis factor alpha, and interleukin-1 beta, in the hearts of STZinduced diabetic mice [82]. DOE at $300 \mathrm{mg} / \mathrm{kg}$ also had a significant inhibitory impact on hyperglycemia and cardiac hypertrophy [82]. The effects of DOE on DCM were evident. However, the severe cardiac remodeling, such as hypertrophy and fibrosis, during the 8-week period of DM [82], needs to be further confirmed in future studies.
4.12. Fermented Rooibos Extract (FRE). The protective effect of FRE, from the root of a South African plant containing the antioxidant aspalathin [83, 84], was evaluated on DCM in a STZ-induced rat model of DM [84]. The results showed that FRE preserved GSH activity in the cardiomyocytes isolated from the diabetic rats and prevented the cells from $\mathrm{H}_{2} \mathrm{O}_{2}$ or an ischemic solution-induced generation of ROS and apoptosis [84]. This protective effect was more prominent as compared with that of another antioxidant vitamin E [84].

4.13. Ficus racemosa Bark Extract. The Indian medicine Ficus racemosa bark extract, possessing antioxidant activity, was tested in STZ-induced diabetic rats, for its effect on DCM [85]. The extract was found to enhance the activity of SOD and reduce the level of MDA in the hearts of the diabetic rats [85].

4.14. Ginkgo biloba Extract. Ginkgo biloba has various uses in traditional medicine and as a source of food [86, 87]. Fitzl et al. treated STZ-induced diabetic rats with Ginkgo biloba extract and found that Ginkgo biloba extract could prevent the loss of myofibrils and the reduction of cardiomyocyte diameter [88]. Ginkgo biloba extract was able to increase cardiac SOD activity, without altering the mRNA of inducible nitric oxide synthase [88]. Therefore, the protective effect of this natural product on DCM could be due to its action in scavenging upon DM-induced free radicals, but not blocking the source of ROS.

4.15. Kalpaamruthaa. The effect of kalpaamruthaa on DCM was tested in a rat model of T2DM [89]. Kalpaamruthaa was found by Latha et al. to reduce the expression of NOX and endothelial nitric oxide synthase, the effects of which led to a decrease in DM-induced accumulation of cardiac lipid peroxides, proinflammatory cytokines, matrix metalloproteinase-2 and matrix metalloproteinase-9, and cardiac remodeling [89]. A subsequent study by the same group showed that kalpaamruthaa inhibited DM-induced cardiac lipid accumulation, chromatin condensation, and marginalization; increased hepatic antioxidants; improved insulin resistance; and lowered blood glucose level [90]. The ability to inhibit PKC- $\beta$ and enhance Akt activity was suggested to account for the protective effect of kalpaamruthaa on DCM [90]. In a following study, the same group further observed that kalpaamruthaa could increase pancreatic antioxidants and reduce pancreatic lipid peroxides and carbonyl content, markers of injury in the plasma, heart, and liver [91]. The decreased cardiac expression of protease-activated receptor-1 by kalpaamruthaa was indicated for the cardiac protection by kalpaamruthaa [91]. These studies addressed the beneficial role of kalpaamruthaa in protection against DCM. It is needed to clarify the mechanism of this natural product, since it is still unclear whether the protection was due to kalpaamruthaa's alteration of DM or was as a result of other mechanisms. Moreover, several factors were suggested to be the key targets of kalpaamruthaa. It would be helpful to elucidate the exact key factor through 
TABLE 2: Antioxidative natural products in clinical trials of diabetes.

\begin{tabular}{|c|c|c|c|c|}
\hline Name & Disease & Dose & Effect & Ref. \\
\hline $\begin{array}{l}\text { Aloe vera inner leaf } \\
\text { gel powder }\end{array}$ & $\begin{array}{l}\text { Patients with impaired } \\
\text { fasting glucose or } \\
\text { glucose tolerance }\end{array}$ & $\begin{array}{l}\text { UP780 or AC952 at } \\
500 \text { mg, twice a day, } \\
\text { for } 8 \text { weeks }\end{array}$ & $\begin{array}{c}\text { Fasting glucose } \downarrow \text {, glucose tolerance } \uparrow \text {, serum } \\
\text { lipoprotein levels } \downarrow \text { (both UP780 and AC952), } \\
\text { urinary F2-isoprostanes } \downarrow \text { (UP780) }\end{array}$ & [98] \\
\hline Black tea & $\mathrm{T} 2 \mathrm{DM}$ & $\begin{array}{l}2.5 \mathrm{~g} / 200 \mathrm{ml} \text { or } \\
7.5 \mathrm{~g} / 600 \mathrm{ml} / \mathrm{d} \\
\text { for } 12 \text { weeks }\end{array}$ & $\begin{array}{c}\text { Serum glycosylated hemoglobin } \downarrow \text {, cholesterol } \downarrow \text {, } \\
\text { markers of oxidative stress } \downarrow \text {, regulatory T cell } \\
\text { secretion } \uparrow \text {, proinflammatory cells } \downarrow\end{array}$ & [99] \\
\hline Chamomile tea & T2DM & $\begin{array}{l}3 \mathrm{~g} / 150 \mathrm{ml}, 3 \text { times } \\
\text { a day, for } 8 \text { weeks }\end{array}$ & $\begin{array}{c}\text { Serum glycosylated hemoglobin } \downarrow \text {, } \\
\text { malondialdehyde } \downarrow \text {, insulin } \downarrow \text {, insulin resistance } \downarrow \text {, } \\
\text { total antioxidant capacity } \uparrow, \text { SOD } \uparrow \text {, GSH } \uparrow \\
\text { and CAT activity } \uparrow\end{array}$ & {$[100]$} \\
\hline Nigella sativa & $\mathrm{T} 2 \mathrm{DM}$ & $2 \mathrm{~g} /$ day, for 1 year & $\begin{array}{c}\text { Fasting blood glucose } \downarrow \text {, glycosylated hemoglobin } \downarrow \text {, } \\
\text { glucose homeostasis } \uparrow \text {, total antioxidant capacity } \uparrow \text {, } \\
\text { the levels of GSH } \uparrow \text { and SOD } \uparrow\end{array}$ & [101] \\
\hline Phyllanthus emblica & T2DM & $\begin{array}{l}500 \mathrm{mg} \text {, twice daily, } \\
\text { for } 10 \text { days }\end{array}$ & Platelet aggregation $\downarrow$, bleeding and clotting time $\uparrow$ & [102] \\
\hline Aged garlic extract & $\begin{array}{l}\text { Patients with T2DM } \\
\text { and high cardiovascular } \\
\text { risk }\end{array}$ & $\begin{array}{c}1200 \mathrm{mg} / \mathrm{d} \text {, for } \\
4 \text { weeks }\end{array}$ & $\begin{array}{l}\text { No significant beneficial effects on body weight, } \\
\text { blood pressure, lipids, insulin resistance, and } \\
\text { biomarkers of endothelial dysfunction, oxidative } \\
\text { stress, and inflammation. }\end{array}$ & [108] \\
\hline $\begin{array}{l}\text { Salvia miltiorrhiza } \\
\text { hydrophilic extract }\end{array}$ & $\begin{array}{l}\text { Diabetic patients with } \\
\text { chronic heart disease }\end{array}$ & $\begin{array}{l}5 \mathrm{~g} \text {, twice per day, } \\
\text { for } 60 \text { days }\end{array}$ & $\begin{array}{c}\text { Serum MDA } \downarrow \text {, GSH } \uparrow \text {, SOD } \uparrow \text {, paraoxonase } \uparrow \text {, and } \\
\text { glutathione reductase } \uparrow\end{array}$ & [109] \\
\hline
\end{tabular}

T1DM: type 1 diabetes; T2DM: type 2 diabetes; $\uparrow$ : activation or improvement; $\downarrow$ : inhibition or downregulation. Other abbreviations are the same as in Table 1.

which kalpaamruthaa exerts the function by using gene silencing or gene knockout models.

4.16. North American Ginseng (NAG). NAG (Panax quinquefolius) is known to have multiple pharmacological functions due to its diverse phytochemical constituents. NAG was studied for its effect on DCM in both STZ-induced type 1 diabetic mice and $\mathrm{DB} / \mathrm{DB}$ spontaneous type 2 diabetic mice [92]. NAG had the capability to reduce the DM-induced expression of cardiac extracellular matrix proteins and vasoactive factors, as well as cardiac hypertrophy and dysfunction in both types of the mice [92]. The DM-induced cardiac oxidative stress was diminished by NAG, the effect of which might mediate NAG's protection against DCM [92]. Given the diverse phytochemical constituents within NAG, the outcome must be a combination of all the effects exerted by all the constituents. It would be interesting to clarify the key targets of the constituents that may play the major roles in the effect of NAG on DCM. As a result, the most effective constituent and the most potent target could be screened out. This may increase the bioavailability and specificity.

4.17. Pongamia pinnata. Pongamia pinnata is a traditional medicine used in the treatment of DM, and its effect on DCM was tested by using STZ/nicotinamide-induced type 2 diabetic rats [93]. Pongamia pinnata decreased blood glucose level, increased the antioxidants SOD and GSH in the hearts of the diabetic mice, and exhibited cardiac protection against DM-induced oxidative damage, biomarkers for cardiac injury, cardiac remodeling, and dysfunction [93]. The exact target of this natural product was not indicated in this study, which needs to be further elucidated in future studies.
4.18. Syzygium cumini. Syzygium cumini was evaluated in H9c2 cells for its protection against glucose stress-induced injury and was found to attenuate high glucose-induced cell hypertrophy and accumulation of extracellular matrix [94], which are hallmarks of long-term diabetic complications $[95,96]$, including DCM [97].

\section{Clinical Trials}

Despite the reports of animal and cell experiments on the effects of natural products on DCM (Table 1), the use of natural products in clinical trials, to date, has not been conducted. However, the clinical trials of antioxidative natural products in the management of DM should also benefit DCM and may provide clues for the future clinical trials of DCM. Therefore, the natural products used in clinical trials of DM, in terms of their efficacy to inhibit oxidative stress, are listed in Table 2.

5.1. Aloe vera Inner Leaf Gel Powder. Aloe vera inner leaf gel powders (UP780 and AC952) were used in patients with impaired fasting glucose or impaired glucose tolerance during an 8-week period in a double-blind, placebocontrolled study [98]. It was reported that both AC952 and UP780 could markedly reduce fasting glucose and improve glucose tolerance and lipoprotein levels in the plasma [98]. However, the reduction of oxidative stress marker urinary F2-isoprostanes was solely noted for UP780 compared with the placebo.

5.2. Black Tea. Mahmoud et al. tested the effects of black tea ingestion on the secretion of inflammatory cytokines and metabolic biomarkers in 30 patients with T2DM [99]. The 
results indicated that treatment with black tea at 200 or $600 \mathrm{ml}$ per day, for 12 weeks, resulted in significantly decreased glycosylated hemoglobin levels and decreased total serum cholesterol levels and the markers of oxidative stress. Furthermore, the supplementation of black tea could inhibit the inflammatory response including an increase in regulatory $\mathrm{T}$ cell secretion and a decrease in the production of proinflammatory cells [99].

5.3. Chamomile Tea. A single-blind randomized controlled clinical trial was conducted on 64 patients with T2DM to evaluate the effect of the antioxidative natural product chamomile tea [100]. Chamomile tea, at $3 \mathrm{~g} / 150 \mathrm{ml}, 3$ times per day, was administered for 8 weeks and was shown to decrease the concentration of serum glycosylated hemoglobin, MDA, insulin, and improved insulin resistance [100]. Additionally, chamomile tea increased total antioxidant capacity, SOD, GSH, and CAT by $6.81 \%, 26.16 \%, 36.71 \%$, and $45.06 \%$, respectively [100]. This trial indicates that intake of chamomile tea could benefit glycemic control and antioxidant status in patients with T2DM.

5.4. Nigella sativa. The long-term effect of Nigella sativa on T2DM patients taking standard hypoglycemic drugs was evaluated [101]. The 1-year treatment with Nigella sativa led to elevated serum total antioxidant activity and the levels of GSH and SOD, as compared with the non-Nigella sativatreated group [101]. Additionally, a significant decrease in fasting blood glucose and glycosylated hemoglobin and an improvement in insulin resistance and $\beta$-cell activity were observed in the Nigella sativa-treated group [101]. These findings suggest the potential of Nigella sativa supplementation as an alternative method to benefit patients with T2DM.

5.5. Phyllanthus emblica Extract (PEE). PEE has a rich source of vitamin C, which is an important antioxidant that prevents platelet aggregation in healthy individuals and patients with coronary artery disease [102]. The 10-day treatment with PEE, at a dose of $500 \mathrm{mg}$ twice per day, was well tolerated in patients with T2DM, exhibited inhibitory effect on platelet aggregation, and prolonged the bleeding and clotting time, the effects of which were similar to those of the daily treatment with $75 \mathrm{mg}$ clopidogrel or ecosprin [102].

5.6. Aged Garlic Extract. Aged garlic extract has antioxidative and antihyperglycemic effects [103-105]. Supplementation of aged garlic extract in the diet reduced oxidative stress and improved endothelial dysfunction in humans $[106,107]$. In a double-blind randomized placebo-controlled crossover pilot trial in patients with T2DM and high cardiovascular risk $(30 \%$ risk of a cardiovascular event in the next 10 years), the 4 -week treatment with aged garlic extract, administered daily at $1200 \mathrm{mg}$, did not produce significant beneficial effects on body weight, blood pressure, lipids, insulin resistance, and biomarkers of endothelial dysfunction, oxidative stress, and inflammation [108]. Although the authors indicated that the recruitment of patients with higher cardiovascular risk or the supplementation of aged garlic extract for a longer period would produce more pronounced effects [108], the mechanism, dose, and safety of this natural product should be further explored in future studies.

5.7. Salvia miltiorrhiza Hydrophilic Extract (SMHE). A randomized controlled clinical study was conducted, using SMHE, to test the protective and antioxidative properties of the extract in diabetic patients with chronic heart disease [109]. SMHE was administrated at a dose of $5 \mathrm{~g}$, twice per day, to the patients for 60 days in addition to their antihyperglycemic therapies. The serum MDA level was decreased by SMHE on day 30 . On day 60 , the serum GSH, SOD, paraoxonase, and glutathione reductase were significantly increased by SMHE. The lipid levels were not altered by SMHE [109]. This study indicates that SMHE has antioxidative activity and attenuates oxidative stress in diabetic patients with chronic heart disease. Determination of serum biomarkers for cardiac injury, cardiac remodeling, and cardiac dysfunction would be helpful in order to know the cardiac protective effect of SMHE under the diabetic condition.

\section{Conclusions}

Natural products with antioxidative properties have been shown to ameliorate DCM in animal models and cardiomyocytes. Although no natural product has been used in clinical trials specifically targeting DCM, several have been used in clinical trials in patients with DM, even as traditional medicines for the treatment of DM for many years. The capability of the natural products in enhancing serum antioxidative activity and reducing serum oxidative stress may also be beneficial for the amelioration of DCM. Given the antioxidative and even blood glucose-lowering effects of the natural products, they have a great potential for the future clinical use as alternative medicines for the management of DM and DCM.

Despite the bright future of the natural products in the treatment of DCM, a few challenges should be carefully considered before the use of natural products in clinical trials. Natural products have multiple targets. This fact may lead to off-target effects, including both the beneficial and the detrimental. Hence, more selective compounds should be developed. The development of SFN and curcumin, isolated from natural products, is a good example, although the two compounds have multiple targets. In-depth mechanisms need to be elucidated, the result of which can provide a solid basis for the development of novel high-selective compounds. In addition, the blood glucose-lowering effect of some natural products is beneficial. However, whether or not natural products lead to unstable blood glucose level in diabetic patients is a concern. Thus, attention should be paid to the fine control of blood glucose level using the combination of standard medicines and natural products as alternative medicines in the treatment of DM or DCM.

In summary, natural products with antioxidative profiles in the management of DCM on one hand have great potentials and face great challenges on the other. The success of natural products in DCM requires extensive studies on the mechanism, specificity, bioavailability, and drug-todrug interactions. 


\section{Conflicts of Interest}

The authors declare that they have no conflicts of interest.

\section{Authors' Contributions}

Bingdi Yan and Jin Ren contributed equally to this work.

\section{Acknowledgments}

This work is supported by the Natural Science Foundation of Jilin Province, China (20150307003YY), to Junling Yang.

\section{References}

[1] J. E. Shaw, R. A. Sicree, and P. Z. Zimmet, "Global estimates of the prevalence of diabetes for 2010 and 2030," Diabetes Research and Clinical Practice, vol. 87, no. 1, pp. 4-14, 2010.

[2] T. Miki, S. Yuda, H. Kouzu, and T. Miura, "Diabetic cardiomyopathy: pathophysiology and clinical features," Heart Failure Reviews, vol. 18, no. 2, pp. 149-166, 2013.

[3] S. A. Hayat, B. Patel, R. S. Khattar, and R. A. Malik, "Diabetic cardiomyopathy: mechanisms, diagnosis and treatment," Clinical Science, vol. 107, no. 6, pp. 539-557, 2004.

[4] A. Aneja, W. H. Tang, S. Bansilal, M. J. Garcia, and M. E. Farkouh, "Diabetic cardiomyopathy: insights into pathogenesis, diagnostic challenges, and therapeutic options," The American Journal of Medicine, vol. 121, no. 9, pp. 748-757, 2008.

[5] A. Marcinkiewicz, S. Ostrowski, and J. Drzewoski, "Can the onset of heart failure be delayed by treating diabetic cardiomyopathy?," Diabetology and Metabolic Syndrome, vol. 9, p. 21, 2017.

[6] S. Boudina and E. D. Abel, "Diabetic cardiomyopathy revisited," Circulation, vol. 115, no. 25, pp. 3213-3223, 2007.

[7] S. Arkat, P. Umbarkar, S. Singh, and S. L. Sitasawad, "Mitochondrial peroxiredoxin-3 protects against hyperglycemia induced myocardial damage in diabetic cardiomyopathy," Free Radical Biology \& Medicine, vol. 97, pp. 489-500, 2016.

[8] V. W. Fischer, H. B. Barner, and M. L. Leskiw, "Capillary basal laminar thickness in diabetic human myocardium," Diabetes, vol. 28, no. 8, pp. 713-719, 1979.

[9] S. M. Factor, E. M. Okun, and T. Minase, "Capillary microaneurysms in the human diabetic heart," The New England Journal of Medicine, vol. 302, no. 7, pp. 384-388, 1980.

[10] L. M. D. Delbridge, K. M. Mellor, D. J. Taylor, and R. A. Gottlieb, "Myocardial stress and autophagy: mechanisms and potential therapies," Nature Reviews Cardiology, vol. 14, 2017.

[11] Q. Liu, S. Wang, and L. Cai, "Diabetic cardiomyopathy and its mechanisms: role of oxidative stress and damage," Journal of Diabetes Investigation, vol. 5, no. 6, pp. 623634, 2014.

[12] M. Hayyan, M. A. Hashim, and I. M. AlNashef, "Superoxide ion: generation and chemical implications," Chemical Reviews, vol. 116, no. 5, pp. 3029-3085, 2016.

[13] K. Sharma, "Mitochondrial hormesis and diabetic complications," Diabetes, vol. 64, no. 3, pp. 663-672, 2015.

[14] F. Giacco and M. Brownlee, "Oxidative stress and diabetic complications," Circulation Research, vol. 107, no. 9, pp. 1058-1070, 2010.
[15] Y. Kayama, U. Raaz, A. Jagger et al., "Diabetic cardiovascular disease induced by oxidative stress," International Journal of Molecular Sciences, vol. 16, no. 10, pp. 25234-25263, 2015.

[16] T. W. Kensler, N. Wakabayashi, and S. Biswal, "Cell survival responses to environmental stresses via the Keap1-Nrf2-ARE pathway," Annual Review of Pharmacology and Toxicology, vol. 47, pp. 89-116, 2007.

[17] Q. Ma, "Transcriptional responses to oxidative stress: pathological and toxicological implications," Pharmacology \& Therapeutics, vol. 125, no. 3, pp. 376-393, 2010.

[18] H. Wu, L. Kong, Y. Cheng et al., "Metallothionein plays a prominent role in the prevention of diabetic nephropathy by sulforaphane via up-regulation of Nrf2," Free Radical Biology \& Medicine, vol. 89, pp. 431-442, 2015.

[19] W. Sun, X. Liu, H. Zhang et al., "Epigallocatechin gallate upregulates NRF2 to prevent diabetic nephropathy via disabling KEAP1," Free Radical Biology \& Medicine, vol. 108, pp. 840-857, 2017.

[20] X. He and Q. Ma, "NRF2 cysteine residues are critical for oxidant/electrophile-sensing, Kelch-like ECH-associated protein-1-dependent ubiquitination-proteasomal degradation, and transcription activation," Molecular Pharmacology, vol. 76, no. 6, pp. 1265-1278, 2009.

[21] M. McMahon, K. Itoh, M. Yamamoto, and J. D. Hayes, "Keap1-dependent proteasomal degradation of transcription factor Nrf2 contributes to the negative regulation of antioxidant response element-driven gene expression," The Journal of Biological Chemistry, vol. 278, no. 24, pp. 21592-21600, 2003.

[22] H. Wu, L. Kong, Y. Tan et al., "C66 ameliorates diabetic nephropathy in mice by both upregulating NRF2 function via increase in miR-200a and inhibiting miR-21," Diabetologia, vol. 59, no. 7, pp. 1558-1568, 2016.

[23] W. Dong, Y. Jia, X. Liu et al., "Sodium butyrate activates NRF2 to ameliorate diabetic nephropathy possibly via inhibition of HDAC," The Journal of Endocrinology, vol. 232, no. 1, pp. 71-83, 2017.

[24] M. Ramos-Gomez, M. K. Kwak, P. M. Dolan et al., "Sensitivity to carcinogenesis is increased and chemoprotective efficacy of enzyme inducers is lost in nrf2 transcription factor-deficient mice," Proceedings of the National Academy of Sciences of the United States of America, vol. 98, no. 6, pp. 3410-3415, 2001.

[25] H. Y. Cho, S. P. Reddy, M. Yamamoto, and S. R. Kleeberger, "The transcription factor NRF2 protects against pulmonary fibrosis," The FASEB Journal, vol. 18, no. 11, pp. 12581260, 2004.

[26] X. He, G. X. Lin, M. G. Chen, J. X. Zhang, and Q. Ma, "Protection against chromium (VI)-induced oxidative stress and apoptosis by Nrf2. Recruiting Nrf2 into the nucleus and disrupting the nuclear Nrf2/Keap1 association," Toxicological Sciences, vol. 98, no. 1, pp. 298-309, 2007.

[27] Y. Wang, H. Wu, Y. Xin et al., "Sulforaphane prevents angiotensin II-induced testicular cell death via activation of NRF2," Oxidative Medicine and Cellular Longevity, vol. 2017, Article ID 5374897, 12 pages, 2017.

[28] M. Xue, Q. Qian, A. Adaikalakoteswari, N. Rabbani, R. Babaei-Jadidi, and P. J. Thornalley, "Activation of NF-E2related factor-2 reverses biochemical dysfunction of endothelial cells induced by hyperglycemia linked to vascular disease," Diabetes, vol. 57, no. 10, pp. 2809-2817, 2008. 
[29] X. He, H. Kan, L. Cai, and Q. Ma, "Nrf2 is critical in defense against high glucose-induced oxidative damage in cardiomyocytes," Journal of Molecular and Cellular Cardiology, vol. 46, no. 1, pp. 47-58, 2009.

[30] K. Y. Hur, S. H. Kim, M. A. Choi et al., "Protective effects of magnesium lithospermate $\mathrm{B}$ against diabetic atherosclerosis via Nrf2-ARE-NQO1 transcriptional pathway," Atherosclerosis, vol. 211, no. 1, pp. 69-76, 2010.

[31] J. Gu, Y. Cheng, H. Wu et al., "Metallothionein is downstream of Nrf2 and partially mediates sulforaphane prevention of diabetic cardiomyopathy," Diabetes, vol. 66, no. 2, pp. 529-542, 2017

[32] Y. Liu, C. Liang, X. Liu et al., "AGEs increased migration and inflammatory responses of adventitial fibroblasts via RAGE, MAPK and NF- $\kappa \mathrm{B}$ pathways," Atherosclerosis, vol. 208, no. 1, pp. 34-42, 2010.

[33] O. Hori, J. Brett, T. Slattery et al., "The receptor for advanced glycation end products (RAGE) is a cellular binding site for amphoterin. Mediation of neurite outgrowth and co-expression of rage and amphoterin in the developing nervous system," The Journal of Biological Chemistry, vol. 270, no. 43, pp. 25752-25761, 1995.

[34] A. Vesikansa, P. Sakha, J. Kuja-Panula et al., "Expression of GluK1c underlies the developmental switch in presynaptic kainate receptor function," Scientific Reports, vol. 2, p. 310, 2012.

[35] G. Lazaros, D. Tsiachris, C. Vlachopoulos et al., "Distinct association of admission hyperglycemia with one-year adverse outcome in diabetic and non-diabetic patients with acute ST-elevation myocardial infarction," Hellenic Journal of Cardiology, vol. 54, no. 2, pp. 119-125, 2013.

[36] H. J. Huttunen, J. Kuja-Panula, G. Sorci, A. L. Agneletti, R. Donato, and H. Rauvala, "Coregulation of neurite outgrowth and cell survival by amphoterin and S100 proteins through receptor for advanced glycation end products (RAGE) activation," The Journal of Biological Chemistry, vol. 275, no. 51, pp. 40096-40105, 2000.

[37] M. Usami, Y. Sakata, D. Nakatani et al., "Effect of intracoronary thrombectomy on 30-day mortality in non-diabetic patients with acute hyperglycemia after acute myocardial infarction," Journal of Cardiology, vol. 53, no. 3, pp. 429-436, 2009.

[38] A. Bierhaus, P. M. Humpert, M. Morcos et al., "Understanding RAGE, the receptor for advanced glycation end products," Journal of Molecular Medicine, vol. 83, no. 11, pp. 876-886, 2005.

[39] M. P. Wautier, O. Chappey, S. Corda, D. M. Stern, A. M. Schmidt, and J. L. Wautier, "Activation of NADPH oxidase by AGE links oxidant stress to altered gene expression via RAGE," American Journal of Physiology Endocrinology and Metabolism, vol. 280, no. 5, pp. E685-E694, 2001.

[40] H. Cai, "NAD(P)H oxidase-dependent self-propagation of hydrogen peroxide and vascular disease," Circulation Research, vol. 96, no. 8, pp. 818-822, 2005.

[41] R. M. Maalouf, A. A. Eid, Y. C. Gorin et al., "Nox4-derived reactive oxygen species mediate cardiomyocyte injury in early type 1 diabetes," American Journal of Physiology Cell Physiology, vol. 302, no. 3, pp. C597-C604, 2012.

[42] T. Ago, J. Kuroda, J. Pain, C. Fu, H. Li, and J. Sadoshima, "Upregulation of Nox4 by hypertrophic stimuli promotes apoptosis and mitochondrial dysfunction in cardiac myocytes," Circulation Research, vol. 106, no. 7, pp. 1253-1264, 2010.
[43] E. Pedruzzi, C. Guichard, V. Ollivier et al., "NAD(P)H oxidase Nox-4 mediates 7-ketocholesterol-induced endoplasmic reticulum stress and apoptosis in human aortic smooth muscle cells," Molecular and Cellular Biology, vol. 24, no. 24, pp. 10703-10717, 2004.

[44] K. Schroder, M. Zhang, S. Benkhoff et al., "Nox4 is a protective reactive oxygen species generating vascular NADPH oxidase," Circulation Research, vol. 110, no. 9, pp. 1217-1225, 2012.

[45] S. I. Dikalov, A. E. Dikalova, A. T. Bikineyeva, H. H. Schmidt, D. G. Harrison, and K. K. Griendling, "Distinct roles of Nox1 and Nox4 in basal and angiotensin II-stimulated superoxide and hydrogen peroxide production," Free Radical Biology \& Medicine, vol. 45, no. 9, pp. 1340-1351, 2008.

[46] D. Zheng, S. Dong, T. Li et al., "Exogenous hydrogen sulfide attenuates cardiac fibrosis through reactive oxygen species signal pathways in experimental diabetes mellitus models," Cellular Physiology and Biochemistry, vol. 36, no. 3, pp. 917-929, 2015.

[47] C. Antoniades, C. Bakogiannis, D. Tousoulis et al., "Preoperative atorvastatin treatment in CABG patients rapidly improves vein graft redox state by inhibition of Racl and NADPH-oxidase activity," Circulation, vol. 122, Supplement 11, pp. S66-S73, 2010.

[48] J. K. Bendall, A. C. Cave, C. Heymes, N. Gall, and A. M. Shah, "Pivotal role of a gp91(phox)-containing NADPH oxidase in angiotensin II-induced cardiac hypertrophy in mice," Circulation, vol. 105, no. 3, pp. 293-296, 2002.

[49] R. Singh, N. Kaur, L. Kishore, and G. K. Gupta, "Management of diabetic complications: a chemical constituents based approach," Journal of Ethnopharmacology, vol. 150, no. 1, pp. 51-70, 2013.

[50] D. D. Zhang, "Mechanistic studies of the Nrf2-Keap1 signaling pathway," Drug Metabolism Reviews, vol. 38, no. 4, pp. 769-789, 2006.

[51] H. Zheng, S. A. Whitman, W. Wu et al., "Therapeutic potential of Nrf2 activators in streptozotocin-induced diabetic nephropathy," Diabetes, vol. 60, no. 11, pp. 30553066, 2011.

[52] G. Negi, A. Kumar, and S. S. Sharma, "Nrf2 and NF- $\kappa$ B modulation by sulforaphane counteracts multiple manifestations of diabetic neuropathy in rats and high glucose-induced changes," Current Neurovascular Research, vol. 8, no. 4, pp. 294-304, 2011.

[53] G. V. Velmurugan, N. R. Sundaresan, M. P. Gupta, and C. White, "Defective Nrf2-dependent redox signalling contributes to microvascular dysfunction in type 2 diabetes," Cardiovascular Research, vol. 100, no. 1, pp. 143-150, 2013.

[54] S. A. Whitman, M. Long, G. T. Wondrak, H. Zheng, and D. D. Zhang, "Nrf2 modulates contractile and metabolic properties of skeletal muscle in streptozotocin-induced diabetic atrophy," Experimental Cell Research, vol. 319, no. 17, pp. 2673-2683, 2013.

[55] D. D. Zhang and M. Hannink, "Distinct cysteine residues in Keap1 are required for Keap1-dependent ubiquitination of Nrf2 and for stabilization of Nrf2 by chemopreventive agents and oxidative stress," Molecular and Cellular Biology, vol. 23, no. 22, pp. 8137-8151, 2003.

[56] Y. Bai, W. Cui, Y. Xin et al., "Prevention by sulforaphane of diabetic cardiomyopathy is associated with up-regulation of Nrf2 expression and transcription activation," Journal of Molecular and Cellular Cardiology, vol. 57, pp. 82-95, 2013. 
[57] Z. Zhang, S. Wang, S. Zhou et al., "Sulforaphane prevents the development of cardiomyopathy in type 2 diabetic mice probably by reversing oxidative stress-induced inhibition of LKB1/AMPK pathway," Journal of Molecular and Cellular Cardiology, vol. 77, pp. 42-52, 2014.

[58] H. Wu, S. Zhou, L. Kong et al., "Metallothionein deletion exacerbates intermittent hypoxia-induced renal injury in mice," Toxicology Letters, vol. 232, no. 2, pp. 340-348, 2014.

[59] Z. Bahadoran, M. Tohidi, P. Nazeri, M. Mehran, F. Azizi, and P. Mirmiran, "Effect of broccoli sprouts on insulin resistance in type 2 diabetic patients: a randomized double-blind clinical trial," International Journal of Food Sciences and Nutrition, vol. 63, no. 7, pp. 767-771, 2012.

[60] V. Karuppagounder, S. Arumugam, V. V. Giridharan et al., "Tiny molecule, big power: multi-target approach for curcumin in diabetic cardiomyopathy," Nutrition, vol. 34, pp. 47-54, 2017.

[61] O. M. Abo-Salem, G. I. Harisa, T. M. Ali, e.-S M. ElSayed, and F. M. Abou-Elnour, "Curcumin ameliorates streptozotocin-induced heart injury in rats," Journal of Biochemical and Molecular Toxicology, vol. 28, no. 6, pp. 263-270, 2014.

[62] W. Yu, J. Wu, F. Cai et al., "Curcumin alleviates diabetic cardiomyopathy in experimental diabetic rats," PLoS One, vol. 7, no. 12, article e52013, 2012.

[63] V. Soetikno, F. R. Sari, V. Sukumaran et al., "Curcumin prevents diabetic cardiomyopathy in streptozotocin-induced diabetic rats: possible involvement of PKC-MAPK signaling pathway," European Journal of Pharmaceutical Sciences, vol. 47, no. 3, pp. 604-614, 2012.

[64] M. T. Aziz, I. N. El Ibrashy, D. P. Mikhailidis et al., "Signaling mechanisms of a water soluble curcumin derivative in experimental type 1 diabetes with cardiomyopathy," Diabetology and Metabolic Syndrome, vol. 5, no. 1, p. 13, 2013.

[65] W. Yu, W. Zha, Z. Ke et al., "Curcumin protects neonatal rat cardiomyocytes against high glucose-induced apoptosis via PI3K/Akt signalling pathway," Journal of Diabetes Research, vol. 2016, Article ID 4158591, 11 pages, 2016.

[66] Y. Pan, Y. Wang, Y. Zhao et al., "Inhibition of JNK phosphorylation by a novel curcumin analog prevents high glucoseinduced inflammation and apoptosis in cardiomyocytes and the development of diabetic cardiomyopathy," Diabetes, vol. 63, no. 10, pp. 3497-3511, 2014.

[67] Y. Liu, Y. Wang, X. Miao et al., "Inhibition of JNK by compound C66 prevents pathological changes of the aorta in STZ-induced diabetes," Journal of Cellular and Molecular Medicine, vol. 18, no. 6, pp. 1203-1212, 2014.

[68] H. Bao and L. Chen, "Icariin reduces mitochondrial oxidative stress injury in diabetic rat hearts," Zhongguo Zhong Yao Za Zhi, vol. 36, no. 11, pp. 1503-1507, 2011.

[69] W. Yu, W. Zha, S. Guo, H. Cheng, J. Wu, and C. Liu, "Flos Puerariae extract prevents myocardial apoptosis via attenuation oxidative stress in streptozotocin-induced diabetic mice," PLoS One, vol. 9, no. 5, article e98044, 2014.

[70] J. Han, C. Tan, Y. Wang, S. Yang, and D. Tan, "Betanin reduces the accumulation and cross-links of collagen in highfructose-fed rat heart through inhibiting non-enzymatic glycation," Chemico-Biological Interactions, vol. 227, pp. 3744, 2015.

[71] N. Rani, S. Bharti, J. Bhatia, T. C. Nag, R. Ray, and D. S. Arya, "Chrysin, a PPAR- $\gamma$ agonist improves myocardial injury in diabetic rats through inhibiting AGE-RAGE mediated oxidative stress and inflammation," Chemico-Biological Interactions, vol. 250, pp. 59-67, 2016.

[72] L. Bi, X. Tian, F. Dou, L. Hong, H. Tang, and S. Wang, "New antioxidant and antiglycation active triterpenoid saponins from the root bark of Aralia taibaiensis," Fitoterapia, vol. 83, no. 1, pp. 234-240, 2012.

[73] Y. Weng, L. Yu, J. Cui et al., “Antihyperglycemic, hypolipidemic and antioxidant activities of total saponins extracted from Aralia taibaiensis in experimental type 2 diabetic rats," Journal of Ethnopharmacology, vol. 152, no. 3, pp. 553-560, 2014.

[74] M. Xi, C. Hai, H. Tang et al., "Antioxidant and antiglycation properties of triterpenoid saponins from Aralia taibaiensis traditionally used for treating diabetes mellitus," Redox Report, vol. 15, no. 1, pp. 20-28, 2010.

[75] J. Duan, G. Wei, C. Guo et al., "Aralia taibaiensis protects cardiac myocytes against high glucose-induced oxidative stress and apoptosis," The American Journal of Chinese Medicine, vol. 43, no. 6, pp. 1159-1175, 2015.

[76] W. Sun, Z. Zhang, Q. Chen et al., "Magnolia extract (BL153) protection of heart from lipid accumulation caused cardiac oxidative damage, inflammation, and cell death in high-fat diet fed mice," Oxidative Medicine and Cellular Longevity, vol. 2014, Article ID 205849, 13 pages, 2014.

[77] W. C. Chang, Y. M. Yu, Y. M. Hsu et al., "Inhibitory effect of Magnolia officinalis and lovastatin on aortic oxidative stress and apoptosis in hyperlipidemic rabbits," Journal of Cardiovascular Pharmacology, vol. 47, no. 3, pp. 463-468, 2006.

[78] Z. Zhang, J. Chen, S. Zhou et al., "Magnolia bioactive constituent 4-O-methylhonokiol prevents the impairment of cardiac insulin signaling and the cardiac pathogenesis in high-fat diet-induced obese mice," International Journal of Biological Sciences, vol. 11, no. 8, pp. 879-891, 2015.

[79] Z. Zhang, J. Chen, X. Jiang et al., “The magnolia bioactive constituent 4-O-methylhonokiol protects against high-fat diet-induced obesity and systemic insulin resistance in mice," Oxidative Medicine and Cellular Longevity, vol. 2014, Article ID 965954, 10 pages, 2014.

[80] R. Khanra, S. Dewanjee, T. K. Dua et al., “Abroma augusta L. (Malvaceae) leaf extract attenuates diabetes induced nephropathy and cardiomyopathy via inhibition of oxidative stress and inflammatory response," Journal of Translational Medicine, vol. 13, p. 6, 2015.

[81] R. Bhatti, S. Sharma, J. Singh, and M. P. Ishar, "Ameliorative effect of Aegle marmelos leaf extract on early stage alloxaninduced diabetic cardiomyopathy in rats," Pharmaceutical Biology, vol. 49, no. 11, pp. 1137-1143, 2011.

[82] Z. Zhang, D. Zhang, M. Dou, Z. Li, J. Zhang, and X. Zhao, "Dendrobium officinale Kimura et Migo attenuates diabetic cardiomyopathy through inhibiting oxidative stress, inflammation and fibrosis in streptozotocin-induced mice," Biomedicine \& Pharmacotherapy, vol. 84, pp. 1350-1358, 2016.

[83] L. Bramati, M. Minoggio, C. Gardana, P. Simonetti, P. Mauri, and P. Pietta, "Quantitative characterization of flavonoid compounds in rooibos tea (Aspalathus linearis) by LC-UV/ DAD," Journal of Agricultural and Food Chemistry, vol. 50, no. 20, pp. 5513-5519, 2002.

[84] P. V. Dludla, C. J. Muller, J. Louw et al., "The cardioprotective effect of an aqueous extract of fermented rooibos (Aspalathus linearis) on cultured cardiomyocytes derived 
from diabetic rats," Phytomedicine, vol. 21, no. 5, pp. 595$601,2014$.

[85] H. Joshi, D. Vaishnav, G. Sanghvi et al., "Ficus recemosa bark extract attenuates diabetic complications and oxidative stress in STZ-induced diabetic rats," Pharmaceutical Biology, vol. 54, no. 9, pp. 1586-1595, 2016.

[86] A. J. Kellermann and C. Kloft, "Is there a risk of bleeding associated with standardized Ginkgo biloba extract therapy? A systematic review and meta-analysis," Pharmacotherapy, vol. 31, no. 5, pp. 490-502, 2011.

[87] G. X. Wang, F. L. Cao, and J. Chen, "Progress in researches on the pharmaceutical mechanism and clinical application of Ginkgo biloba extract on various kinds of diseases," Chinese Journal of Integrative Medicine, vol. 12, no. 3, pp. 234-239, 2006.

[88] G. Fitzl, R. Martin, D. Dettmer, V. Hermsdorf, H. Drews, and K. Welt, "Protective effects of Gingko biloba extract EGb 761 on myocardium of experimentally diabetic rats. I: ultrastructural and biochemical investigation on cardiomyocytes," Experimental and Toxicologic Pathology, vol. 51, no. 3, pp. 189-198, 1999.

[89] R. Latha, P. Shanthi, and P. Sachdanandam, "Kalpaamruthaa ameliorates myocardial and aortic damage in cardiovascular complications associated with type 2 diabetes mellitus," Canadian Journal of Physiology and Pharmacology, vol. 91, no. 2, pp. 116-123, 2013.

[90] R. Latha, P. Shanthi, and P. Sachdanandam, "Kalpaamruthaa modulates oxidative stress in cardiovascular complication associated with type 2 diabetes mellitus through PKC-beta/ Akt signaling," Canadian Journal of Physiology and Pharmacology, vol. 91, no. 11, pp. 901-912, 2013.

[91] R. Latha, P. Shanthi, and P. Sachdanandam, "Protective role of Kalpaamruthaa in type II diabetes mellitus-induced cardiovascular disease through the modulation of proteaseactivated receptor-1," Pharmacognosy Magazine, vol. 11, Supplement 1, pp. S209-S216, 2015.

[92] S. Sen, S. Chen, Y. Wu, B. Feng, E. K. Lui, and S. Chakrabarti, "Preventive effects of North American ginseng (Panax quinquefolius) on diabetic retinopathy and cardiomyopathy," Phytotherapy Research, vol. 27, no. 2, pp. 290298, 2013.

[93] S. L. Badole, S. M. Chaudhari, G. B. Jangam, A. D. Kandhare, and S. L. Bodhankar, "Cardioprotective activity of Pongamia pinnata in streptozotocin-nicotinamide induced diabetic rats," BioMed Research International, vol. 2015, Article ID 403291, 8 pages, 2015.

[94] N. Atale, M. Chakraborty, S. Mohanty et al., "Cardioprotective role of Syzygium cumini against glucose-induced oxidative stress in H9C2 cardiac myocytes," Cardiovascular Toxicology, vol. 13, no. 3, pp. 278-289, 2013.

[95] C. R. Ban and S. M. Twigg, "Fibrosis in diabetes complications: pathogenic mechanisms and circulating and urinary markers," Vascular Health and Risk Management, vol. 4, no. 3, pp. 575-596, 2008.

[96] H. Wu, L. Kong, S. Zhou et al., "The role of microRNAs in diabetic nephropathy," Journal of Diabetes Research, vol. 2014, Article ID 920134, 12 pages, 2014.

[97] J. Asbun and F. J. Villarreal, “The pathogenesis of myocardial fibrosis in the setting of diabetic cardiomyopathy," Journal of the American College of Cardiology, vol. 47, no. 4, pp. 693-700, 2006.
[98] S. Devaraj, M. Yimam, L. A. Brownell, I. Jialal, S. Singh, and Q. Jia, "Effects of Aloe vera supplementation in subjects with prediabetes/metabolic syndrome," Metabolic Syndrome and Related Disorders, vol. 11, no. 1, pp. 35-40, 2013.

[99] F. Mahmoud, D. Haines, E. Al-Ozairi, and A. Dashti, "Effect of black tea consumption on intracellular cytokines, regulatory $\mathrm{T}$ cells and metabolic biomarkers in type 2 diabetes patients," Phytotherapy Research, vol. 30, no. 3, pp. 454462, 2016.

[100] M. Zemestani, M. Rafraf, and M. Asghari-Jafarabadi, "Chamomile tea improves glycemic indices and antioxidants status in patients with type 2 diabetes mellitus," Nutrition, vol. 32, no. 1, pp. 66-72, 2016.

[101] H. Kaatabi, A. O. Bamosa, A. Badar et al., "Nigella sativa improves glycemic control and ameliorates oxidative stress in patients with type 2 diabetes mellitus: placebo controlled participant blinded clinical trial," PLoS One, vol. 10, no. 2, article e0113486, 2015.

[102] N. Fatima, U. Pingali, and N. Muralidhar, "Study of pharmacodynamic interaction of Phyllanthus emblica extract with clopidogrel and ecosprin in patients with type II diabetes mellitus," Phytomedicine, vol. 21, no. 5, pp. 579-585, 2014.

[103] M. S. Ahmad and N. Ahmed, "Antiglycation properties of aged garlic extract: possible role in prevention of diabetic complications," The Journal of Nutrition, vol. 136, Supplement 3, pp. 796S-799S, 2006.

[104] T. M. Shiju, N. G. Rajesh, and P. Viswanathan, "Renoprotective effect of aged garlic extract in streptozotocin-induced diabetic rats," Indian Journal of Pharmacology, vol. 45, no. 1, pp. 18-23, 2013.

[105] M. Thomson, K. K. Al-Qattan, J. S. Divya, and M. Ali, "Antidiabetic and anti-oxidant potential of aged garlic extract (AGE) in streptozotocin-induced diabetic rats," BMC Complementary and Alternative Medicine, vol. 16, p. 17, 2016.

[106] S. A. Dillon, G. M. Lowe, D. Billington, and K. Rahman, "Dietary supplementation with aged garlic extract reduces plasma and urine concentrations of 8-iso-prostaglandin $\mathrm{F}$ (2 alpha) in smoking and nonsmoking men and women," The Journal of Nutrition, vol. 132, no. 2, pp. 168-171, 2002.

[107] N. Weiss, N. Ide, T. Abahji, L. Nill, C. Keller, and U. Hoffmann, "Aged garlic extract improves homocysteineinduced endothelial dysfunction in macro- and microcirculation," The Journal of Nutrition, vol. 136, Supplement 3, pp. 750S-754S, 2006.

[108] M. Atkin, D. Laight, and M. H. Cummings, "The effects of garlic extract upon endothelial function, vascular inflammation, oxidative stress and insulin resistance in adults with type 2 diabetes at high cardiovascular risk. A pilot double blind randomized placebo controlled trial," Journal of Diabetes and its Complications, vol. 30, no. 4, pp. 723-727, 2016.

[109] Q. Qian, S. Qian, P. Fan, D. Huo, and S. Wang, "Effect of Salvia miltiorrhiza hydrophilic extract on antioxidant enzymes in diabetic patients with chronic heart disease: a randomized controlled trial," Phytotherapy Research, vol. 26, no. 1, pp. 60-66, 2012. 


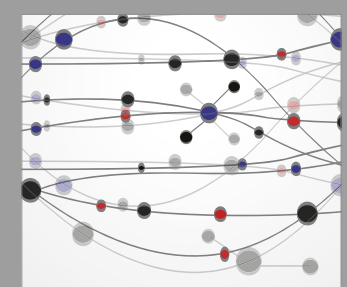

The Scientific World Journal
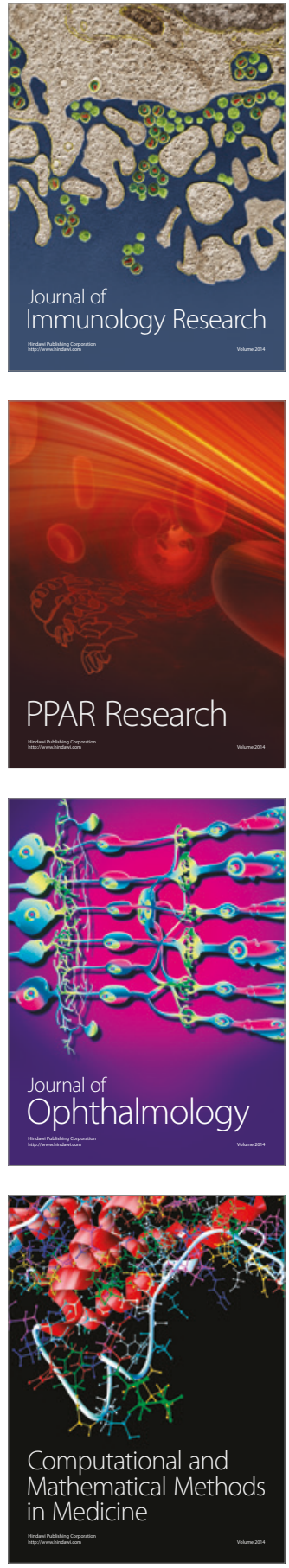

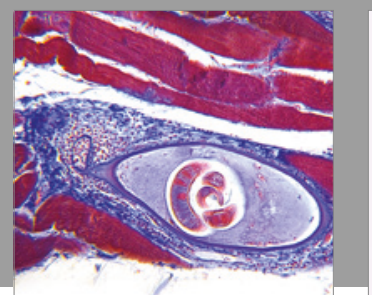

Gastroenterology Research and Practice
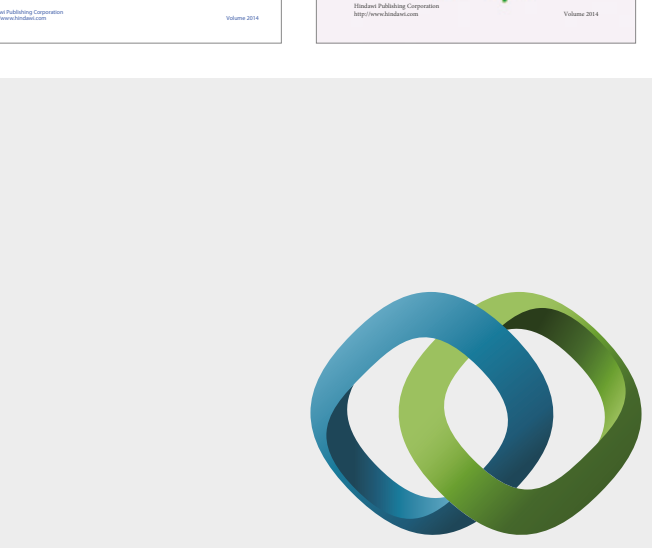

\section{Hindawi}

Submit your manuscripts at

https://www.hindawi.com
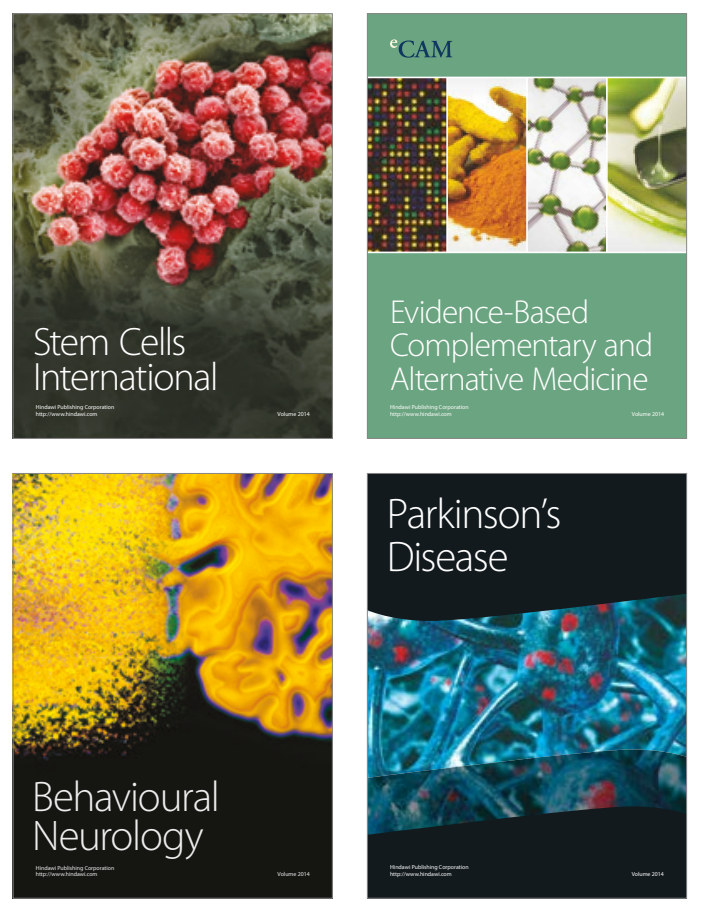
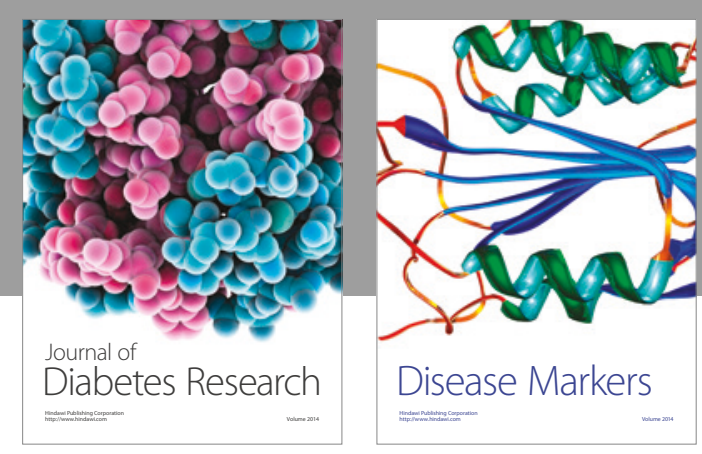

Disease Markers
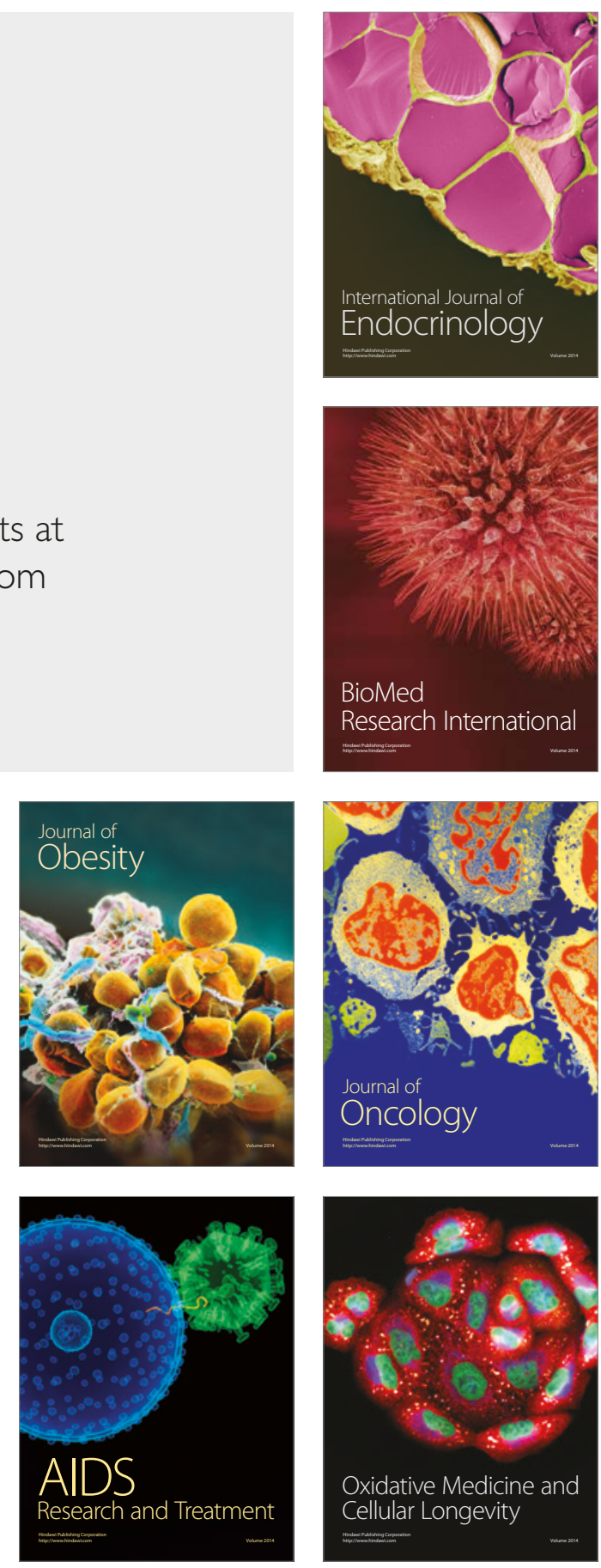